\title{
Activation of cytokines as a mechanism of disease progression in heart failure
}

\author{
Biykem Bozkurt
}

The scientific quest for the basic mechanism(s) responsible for the development and progression of congestive heart failure in humans has been practically exhaustive; none the less, the mechanisms responsible for the decompensation of myocardial function after myocardial injury or haemodynamic overloading, or both, have remained elusive. Initially clinicians viewed heart failure as a problem of excessive salt and water retention that was caused by abnormalities of renal blood flow (the cardiorenal model). As clinicians began to perform careful haemodynamic measurements, it also became apparent that heart failure was accompanied by reduced cardiac output and excessive peripheral vasoconstriction. This led to the development of a cardiocirculatory or haemodynamic model for heart failure, in which heart failure was thought to arise from abnormalities of the pumping capacity of the heart. Neither of these models explained the progression of heart failure. Subsequently neurohormones were considered to lead to disease progression through myocyte loss, progressive myocardial fibrosis, as well as salt and water retention. More recently, it has become evident that another class of biologically active molecules, generally referred to as cytokines are also important in heart failure. ${ }^{1-8}$

\section{General background of cytokines}

The term cytokine is applied to a group of relatively small molecular weight protein molecules (generally $15-30 \mathrm{kDa}$ ) that are secreted by cells in response to a variety of different inducing stimuli. Classically, cytokines are thought to be secreted by neighbouring "producer cells" and to act in an autocrine, juxtacrine or paracrine manner to influence the biological behaviour of neighbouring "target cells" (see Mann and Young" for a brief review). However, when cytokines are overproduced they can "spill over" into the peripheral circulation where they can exert endocrine-like effects. It should be recognised that although cytokines are similar in many respects to polypeptide hormones, cytokines can be produced by a variety of different cell types in a number of different tissues, in contrast with being produced by a specific cell type in a specific organ, as is the case for polypeptide hormones. Thus far two major classes of cytokines have been identified in heart failure: vasoconstrictor cytokines, such as endothelin, and vasodepressor proinflammatory cytokine, such as tumour necrosis factor (TNF) and interleukin 6 (IL6). The group of cytokines that are responsible both for initiating the primary host response to a bacterial infection, as well as initiating the repair of tissue after tissue
Table 1 The potential untoward effects of TNF in heart failure

- Produces left ventricular dysfunction in humans ${ }^{21}$ - Produces pulmonary oedema in humans ${ }^{22}$

- Produces cardiomyopathy in humans ${ }^{23}$

- Promotes left ventricular remodelling experimentally ${ }^{24}$

- Produces abnormalities in myocardial metabolism experimentally ${ }^{25}$

- Produces anorexia and cachexia experimentally ${ }^{26}$

- Produces $\beta$-receptor uncoupling from adenylate cyclase experimentally ${ }^{27}$

- Produces abnormalities of mitochondrial energetics ${ }^{28}$ - Activation of fetal gene programme experimentally ${ }^{29}$

injury have been termed "proinflammatory cytokines."

\section{Effects of cytokines on the heart}

Many aspects of heart failure can be explained by the known biological effects of stress activated proinflammatory cytokines. When expressed at sufficiently high concentration, cytokines can mimic some aspects of heart failure phenotype including but not limited to progressive left ventricular dysfunction, pulmonary oedema, LV remodelling, fetal gene expression, and cardiomyopathy (table 1). The current literature suggests that TNF produces both immediate and delayed negative inotropic effect on myocardial contractility.

Thus the elaboration of cytokines may represent much like neurohormones, a biological mechanism that is responsible for producing symptoms in patients with heart failure.

Cytokines are thought to exert their effects by binding to specific receptors on the surface of the cell including the adult cardiac myocyte. In the case of TNF, this protein is known to bind to two types of TNF receptors: TNFR1 (p 55) and TNFR2 ( $p$ 75) receptor. Recent studies have shown that the adult human cardiac myocytes express both types of TNF receptors, and that the type 1 receptor is responsible for mediating the negative inotropic effects of TNF. ${ }^{9} 17$ Studies have also shown that when both TNF receptors are proteolytically cleaved from the cell membrane, they exist in the circulation as circulating soluble receptors referred to as sTNFR1 and sTNFR2 respectively. Interestingly, both these receptors retain their ability to bind their ligand, as well as to inhibit the cytotoxic activities of TNF. It has been suggested that they may serve as "biological buffers" that are capable of rapidly neutralising the highly cytotoxic activities of TNF. ${ }^{13}$

Considerable interest in the potential role of IL6 in the heart has been generated by the observation that increased levels of IL6 are expressed in humans following acute myocardial infarction. ${ }^{14}$ The human IL6 receptor is a 
Table 2 Cytokines and cytokine receptors in heart failure

\begin{tabular}{|c|c|c|c|c|c|c|c|c|}
\hline & \multicolumn{5}{|c|}{ Cytokines } & \multicolumn{3}{|c|}{ Cytokine receptors } \\
\hline & $T N F$ & $I L 1$ & $I L 2$ & IL6 & $I F N \gamma$ & STNFR1 & STNFR2 & $I L 1 R A$ \\
\hline Levine $^{1}$ & + & nd & nd & nd & nd & nd & nd & nd \\
\hline McMurray $^{2}$ & + & nd & nd & nd & nd & nd & nd & nd \\
\hline Dutka $^{3}$ & + & nd & nd & nd & nd & nd & nd & nd \\
\hline Wiederman $^{30}$ & + & - & nd & + & - & nd & nd & nd \\
\hline $\mathrm{Katz}^{4}$ & + & - & + & nd & nd & nd & nd & nd \\
\hline Matsumori ${ }^{5}$ & + & - & - & - & - & nd & nd & nd \\
\hline Ferrari $^{31}$ & + & nd & nd & nd & nd & + & + & nd \\
\hline Pritchett $^{32}$ & - & nd & nd & nd & nd & nd & nd & nd \\
\hline Torre $^{17}$ & + & nd & nd & nd & nd & + & + & nd \\
\hline Torre $^{7}$ & + & nd & nd & + & nd & nd & nd & nd \\
\hline Milani $^{33}$ & + & nd & nd & nd & nd & + & nd & + \\
\hline Munger $^{34}$ & - & - & nd & + & nd & nd & nd & nd \\
\hline Testa $^{35}$ & + & + & - & + & nd & nd & + & + \\
\hline Anker $^{36}$ & + & nd & nd & nd & nd & nd & nd & nd \\
\hline McGowen $^{37}$ & + & nd & nd & + & nd & nd & nd & nd \\
\hline Mohler $^{38}$ & + & nd & nd & + & nd & nd & nd & nd \\
\hline Nishigaki $^{39}$ & + & nd & nd & + & nd & nd & nd & nd \\
\hline Anker $^{40}$ & + & nd & nd & nd & nd & + & + & nd \\
\hline
\end{tabular}

nd: not done, + : levels increased, $-:$ levels not increased.

glycoprotein consisting of two functional chains: a $80 \mathrm{kDa}$ IL6 binding protein, termed IL6R, and a $130 \mathrm{kDa}$ "docking protein," termed gp 130, which transmits the intracellular signal. ${ }^{10}$ Specific information on the presence or absence of the IL6 receptor in the heart is not yet available. Genetic mice that are deficient in gp130 are embryonic lethal because their hearts do not develop. For a more detailed discussion of the biology of these molecules and their receptors, the interested reader is referred to a recent review article on proinflammatory cytokines and the heart. ${ }^{9}$

\section{Cytokines and heart failure}

SITES AND SOURCES

Following the original description of increased cytokine levels in heart failure ${ }^{1}$; there was speculation that activation of the immune system was responsible for the increased levels of cytokines in heart failure. Monocytes have traditionally been held as a major source of cytokine production. Neopterin levels, which are markers for cytokine production, are increased in patients with heart failure. However, it is important to recognise that TNF itself can stimulate monocytes to produce neopterin, accordingly, it is unclear whether increased neopterin levels represent primary activation of mononuclear cells with secondary production of TNF or whether TNF simulates the mononuclear cell that subsequently releases neopterin. ${ }^{30}$ The immune system being the sole source of cytokines was challenged by the observation that the heart is capable of producing TNF, IL1 and IL6. Haemodynamic overloading or myocardial stretch provokes de novo TNF mRNA and protein synthesis experimentally. ${ }^{16}$ Interestingly, neither TNF mRNA nor protein were expressed in myocytes subjected to normal haemodynamic loading conditions. Thus, conditions that are known to eventuate the development of heart failure also lead to TNF overproduction. The clinical importance of these experimental findings is further substantiated by the observation that TNF mRNA and protein are present in failing hearts whereas not detectable in non-failing human hearts. These data suggest that the proinflammatory cytokines are elaborated by the heart in certain forms of stress, and that increased levels of TNF may represent spill over of cytokines that were produced within the myocardium. An intriguing possibility is that there may be "cross-talk" between cardiovascular and the immune systems. Other hypotheses are that a decreased cardiac output in the heart failure leads to elaboration of TNF by underperfused metabolic tissues or that increased levels of TNF in heart failure may result from altered distribution, degradation, or clearance of these molecules from plasma.

WHICH CYTOKINES ARE INCREASED IN HEART FAILURE?

Table 2 provides a summary of the studies that examined circulating cytokine levels in patients with symptomatic heart failure.

A number of studies consistently found increased levels of TNF in congestive heart failure, comparatively less is known about circulating levels of IL1, IL2, IL6 and IFN $\gamma$. Moreover, several studies suggest that there is an increasing cytokine production in direct relation to severity of disease. ${ }^{7313537}$ There is progressive increase in TNF levels in relation to deteriorating NYHA functional class. Moreover, there is relation to increased mortality with increasing levels of TNF in analysis of cytokine levels in SOLVD database ${ }^{7}$ and VEST (unpublished data). Similar to increased levels of neurohormones, TNF levels may be predictive of NYHA class and clinical outcome.

Most studies have found increased levels of IL6 in heart failure although this has not been true for all studies. Although the mechanism for increased levels of IL6 in heart failure is not known, it is interesting to note that TNF is sufficient to induce IL6 gene and protein expression in a variety of cell types ${ }^{10}$ suggesting there may be a cytokine cascade in the setting of heart failure. ${ }^{37}$

At the time of writing, there is little clinical evidence that supports an important role for IL1, IL2 or IFN $\gamma$ in heart failure. Thus in summary, on the basis of clinical material extant at this time, the preponderance of clinical data suggest that both TNF and IL6 constitute the major portfolio of stress activated cytokines in heart failure.

\section{WHICH CYTOKINE RECEPTORS ARE INCREASED IN} HEART FAILURE?

There are increased circulating levels of cytokine receptors and cytokine receptor antagonists (RA) in heart failure, including sTNFR1, sTNFR2, IL1RA and IL6R. Thus far two reports have demonstrated increased levels of sTNFR1 and sTNFR2 in patients with heart failure. In the report by Ferrari et al, circulating levels of sTNFR2 correlated independently with worse short-term prognosis. Although clinical significance of this is unclear, it has been suggested that sTNFRs may act as a biological reservoir for TNF that stabilises the molecule and slowly releases this cytokine into the circulation. 
SUPPRESSION OF CYTOKINE PRODUCTION AS A THERAPEUTIC PARADIGM IN HEART FAILURE

One natural question arises from the above discussion whether modulation of cytokine production or cytokine bioactivity may be a method for treating patients with heart failure. There are several preliminary studies that may answer this question.

Parillo and colleagues ${ }^{41}$ randomly assigned 102 patients to either treatment with prednisone or placebo. After three months of treatment, they observed an increase in ejection fraction of $>5 \%$ in $53 \%$ of the patients receiving prednisone, whereas only $27 \%$ of the controls had a significant improvement in ejection fraction $(p=0.005)$. Overall, the mean ejection fraction increased $4.3 \%$ in the prednisone group, as compared with $2.1 \%$ in the control group $(p=0.054)$. The patients were then further categorised respectively in two separately randomised subgroups: "reactive" patients, who had fibroblastic or lymphocytic infiltration or immunoglobulin deposition on endomyocardial biopsy, a positive gallium scan, or an increased erythrocyte sedimentation rate; or "non-reactive" patients, who had none of these features. At three months, $67 \%$ of the reactive patients who received prednisone had improvement in LV function, as compared with $28 \%$ of the reactive controls $(p=0.004)$. In contrast, non-reactive patients did not improve with prednisone. Although specific cytokine levels were not measured in this study, their data suggest that patients with idiopathic dilated cardiomyopathy may have some improvement given a high dose of prednisone daily. This early study raises the possibility that suppression of cytokine production may be used as a therapeutic tool in treating patients with heart failure.

Another potentially important pharmacological method for suppressing cytokine production is through the use of agents that increase cAMP levels, such as dobutamine, which as noted above, will suppress TNF production. ${ }^{42}$ It is therefore tempting to speculate that one of the mechanisms for the sustained benefit of intravenous infusions of dobutamine may be through suppression of proinflammatory cytokines such as TNF. However, this point of view is not supported by a recent study, in which it was shown that treatment with either intravenous dobutamine or milnirone had no effect in terms of decreasing circulating TNF levels. ${ }^{33}$

Mohler and colleagues ${ }^{38}$ examined the effects of amlodipine on circulating levels of TNF and IL6 in a subset analysis of patients enrolled in the PRAISE trial. They observed that although treatment with amlodipine had no effect on TNF levels, there was a statistically significant decrease in IL6 levels after 24 weeks of treatment.

THERAPEUTIC EFFECT OF SOLUBLE TNF RECEPTOR IN HEART FAILURE PATIENTS

In a recent report using a soluble TNF receptor (etanercept, p75) that neutralises the biological effect of circulating TNF, Deswal et al showed that there was an improvement in functional status and quality of life in 12 patients with advanced heart failure. ${ }^{43}$

Subsequently a second multidose phase I trial was conducted with etanercept, p75 TNF receptor fusion protein in 47 patients with NYHA class III-IV heart failure and $\mathrm{EF}<35 \%$ at three sites. This was a double blind, placebo controlled and randomised study, using placebo or etanercept 5 or $12 \mathrm{mg} / \mathrm{m}^{2}$ as subcutaneous injections twice a week for three months. The primary objective was safety; secondary objectives were NYHA functional class, LVEF by MUGA, quality of life and clinical composite score. In this study etanercept was well tolerated, improvement in LVEF, quality of life, and clinical composite scores were greatest in the $12 \mathrm{mg} / \mathrm{m}^{2}$ group. ${ }^{44}$ There is also evidence of early reverse remodelling of the left ventricle in heart failure after treatment with etanercept, p $75 \mathrm{TNF}$ receptor fusion protein. After three months of treatment, the LV end diastolic diameter, LV volumes and LV mass seem to decrease in the treated group compared with placebo. This was accompanied by improvement in LVEF and cardiac output measured by echocardiography. ${ }^{45}$

A multicentre randomised phase III study, named Renaissance (Randomized Etanercept North American Strategy to Study Antagonism of Cytokines) is currently being conducted in more than 100 US, European and Australian centres to study the effects of etanercept in approximately 900 patients with advanced heart failure.

\section{Summary}

The cytokine hypothesis for heart failure suggests that heart failure progresses because cytokine cascades that are activated after myocardial injury exert deleterious effects on the heart and circulation. It bears emphasis that the cytokine hypothesis does not imply that cytokines cause heart failure in itself, but rather that the overexpression of cytokines contributes to the progression of heart failure once LV dysfunction ensues. The stress activated cytokines can exert autocrine/paracrine effects within the myocardium by binding to specific cytokine receptors. However, if cytokine expression is excessive these molecules may produce LV dysfunction and LV dilatation.

1 Levine B, Kalman J, Mayer L, Fillit HM, Packer M. Elevated circulating levels of tumor necrosis factor in severe chronic heart failure. N Engl J Med 1990;223:236-41.

2 McMurray J, Abdullah I, Dargie HJ, Shapiro D. Increased concentrations of tumour necrosis factor in "cachectic" patients with severe chronic heart failure. Br Heart J 1991; 66:356-8.

3 Dutka DP, Elborn JS, Delamere F, Shale DJ, Morris GK. Tumour necrosis factor-alpha in severe congestive cardiac failure. Br Heart J 1993;70:141-3.

4 Katz SD, Rao R, Berman JW, et al. Pathophysiological correlates of increased serum tumor necrosis factor in patients with congestive heart failure: relation to nitric oxidedependent vasodilation in the forearm circulation. Circulation 1994;90:12-16.

5 Matsumori A, Yamada T, Suzuki H, Matoba Y, Sasayama S. Increased circulating cytokines in patients with myocarditis and cardiomyopathy. Br Heart J 1994;72:561-6.

6 Tsutamoto T, Hisanaga T, Wada A, Maeda Y, Fukai D. Plasma concentration of interleukin- 6 as a marker of prognosis in patients with chronic congestive heart failure Circulation 1994;90:I-381.

7 Torre-Amione G, Kapadia S, Benedict C, Oral H, Young JB, Mann DL. Proinflammatory cytokine levels in patients with depressed left ventricular ejection fraction: a report from the studies of left ventricular dysfunction (SOLVD). J rom the studies of left ventricular 
8 Mann DL, Young JB. Basic mechanisms in congestive heart failure: recognizing the role of proinflammatory cytokines. Chest 1994:105:897-904.

9 Torre-Amione G, Kapadia S, Lee J, Bies RD, Lebovitz R, Mann DL. Expression and functional significance of tumor necrosis factor receptors in human myocardium. Circulation 1995;92:1487-93.

10 Hirano T. Interleukin-6. In: Thompson A, ed. The cytokine handbook. Boston: Academic Press, 1991:169-90.

11 Oral H, Kapadia S, Nakano M, et al. Tumor necrosis factor- $\alpha$ and the failing human heart. Clin Cardiol 1995; 18:IV-20-7.

12 Yokoyama T, Vaca L, Rossen RD, Durante W, Hazarika P, Mann DL. Cellular basis for the negative inotropic effects of tumor necrosis factor-alpha in the adult mammalian heart. J Clin Invest 1993;92:2303-12

13 Bozkurt B, Shan K, Seta Y, Oral H, Mann DL. Tumor necrosis factor and tumor necrosis factor receptors in
human heart failure. Heart Failure Reviews 1996;1:21119.

14 Neumann FJ, Ott I, Gawaz M, et al. Cardiac release of cytokines and inflammatory responses in acute myocardial infarction. Circulation 1995;92:748-55.

15 Finkel MS, Oddis CV, Jacob TD, Watkins SC, Hattler BG Simmons RL. Negative inotropic effects of cytokines on the heart mediated by nitric oxide. Science 1992;257:387-9.

16 Kapadia SR, Oral H, Lee J, Nakano M, Taffet GE, Mann DL. Hemodynamic regulation of tumor necrosis factoralpha gene and protein expression in adult feline myocardium. Circ Res 1997;81:187-95.

17 Torre-Amione G, Kapadia S, Lee J, et al. Tumor necrosis factor- $\alpha$ and tumor necrosis factor receptors in the failing human heart. Circulation 1996;93:704-11.

18 Yamauchi-Takihara K, Ihara Y, Ogata A, Yoshizaki K, Azuma J, Kishimoto T. Hypoxic stress induces cardiac myocyte-derived interleukin-6. Circulation 1995;91:

19 Meerson FZ. The failing heart: adaptation and deadaptation. New York: Raven Press, 1983:51-2.

20 Matsumori A, Shioi T, Yamada T, Matsui S, Sasayama S. Vesnarinone, a new inotropic agent, inhibits cytokine production by stimulated human blood from patients with production by stimulated human blood from

21 Suffredini AF, Fromm RE, Parker MM, et al. The cardiovascular response of normal humans to the administration of endotoxin. N Engl J Med 1989;321:280-7.

22 Millar AB, Singer M, Meager A, Foley NM, Johnson NM Rook GA. Tumor necrosis factor in bronchopulmonary secretions of patients with adult respiratory distress syndrome. Lancet 1989;ii:712-13.

23 Hegewisch S, Weh HJ, Hossfeld DK. TNF-induced cardiomyopathy. Lancet 1990;ii:294-5.

24 Pagani FD, Baker LS, Hsi C, Knox M, Fink MP, Visner MS Left ventricular systolic and diastolic dysfunction after infusion of tumor necrosis factor- $\alpha$ in conscious dogs. J Clin Invest 1992;90:389-98.

25 Semb H, Peterson J, Tavernier J, Olivecrona T. Multiple effects of tumor necrosis factor on lipoprotein lipase in effects of tumor necrosis factor on
vivo. J Biol Chem 1987;262:8390-4.

26 Oliff A, Defeo-Jones D, Boyer M, et al. Tumors secreting human TNF/Cachectin induce eachexia in mice. Cell 1987;50:555-63.

27 Chung MK, Gulick TS, Rotondo RE, Schreiner GF, Lange LG. Mechanism of action of cytokine inhibition of $\beta$-adrenergic agonist stimulation of cyclic AMP in rat cardiac myocytes: impairment of signal transduction. Circ Res 1990;67:753-63.

28 Lancaster Jr, Laster SM, Gooding LR. Inhibition of target cell mitochondrial electron transfer by tumor necrosis factor. FEBS Lett 1989;248:169-74.
29 Thaik CM, Calderone A, Takahashi N, Colucci WS. Interleukin-1 beta modulates the growth and phenotype of neonatal rat cardiac myocytes. J Clin Invest 1995;96: 1093-9.

30 Wiedermann CJ, Beimpold H, Herold M, Knapp E, Braunsteiner $\mathrm{H}$. Increased levels of serum neopterin and decreased production of neutrophil superoxide anions in chronic heart failure with elevated levels of tumor necrosis factor-alpha. J Am Coll Cardiol 1993;22:1897-901.

31 Ferrari R, Bachetti T, Confortini R, et al. Tumor necrosis factor soluble receptors in patients with various degrees of congestive heart failure. Circulation 1995;92:1479-86.

32 Prichett G, Cohen HJ, Rao KM, Cobb F, Sullivan M, Currie MS. Tumor necrosis factor, natural killer activity and other measures of immune function and inflammation in elderly men with heart failure. Gerontology 1995;41:4556.

33 Milani RV, Mehra MR, Endres S, et al. The clinical relevance of circulating tumor necrosis factor-alpha in acute decompensated chronic heart failure without cachexia. Chest 1996;110:992-5.

34 Munger MA, Johnson B, Amber IJ, Callahan KS, Gilbert EM. Circulating concentrations of proinflammatory cytokines in mild or moderate heart failure secondary to ischemic or idiopathic dilated cardiomyopathy. Am J Cardiol 1996;77:723-7.

35 Testa $M$, Yeh $M$, Lee $\mathrm{P}$, et al. Circulating levels of cytokines and their endogenous modulators in patients with mild to severe congestive heart failure due to coronary artery disease or hypertension. J Am Coll Cardiol 1996;28:96471 .

36 Anker SD, Chua TP, Ponikowski P, et al. Hormonal changes and catabolic/anabolic imbalance in chronic heart failure and their importance for cardiac cachexia. Circulation $199715 ; 96: 526-34$.

37 MacGowan GA, Mann DL, Kormos RL, Feldman AM, Murali S. Circulating interleukin-6 in severe heart failure. Am J Cardiol 1997;79:1128-31.

38 Mohler ER 3rd, Sorensen LC, Ghali JK, et al. Role of cytokines in the mechanism of action of amlodipine: the PRAISE Heart Failure Trial. Prospective Randomized Amlodipine Survival Evaluation. J Am Coll Cardiol 1997;30:35-41.

39 Nishigaki K, Minatoguchi S, Seishima M, et al. Plasma Fas ligand, an inducer of apoptosis, and plasma soluble Fas, an inhibitor of apoptosis, in patients with chronic congestive heart failure. J Am Coll Cardiol 1997;29:1214-20.

40 Anker SD, Egerer KR, Volk HD, Kox WJ, Poole-Wilson PA, Coats AJ. Elevated soluble CD14 receptors and altered cytokines in chronic heart failure. Am J Cardiol 1997;79: 1426-30.

41 Parrillo JE, Cunnion RE, Epstein SE, et al. A prospective, randomized, controlled trial of prednisone for dilated cardiomyopathy. N Engl J Med 1989;321:1061-8.

42 Sindhwani R, Yuen J, Hirsch H, et al. Reversal of flow state attenuates immune activation in severe decompensated heart failure. [Abstract]. Circulation 1993;88:I-255.

43 Deswal A, Seta Y, Blosch CM, Mann DL. A Phase I trial of tumor necrosis factor receptor-p75 fusion protein (TNFR: $\mathrm{Fc}$ ) in patients with advanced heart failure. [Abstract]. Circulation 1997; (suppl)

44 Bozkurt B, Torre-Amione G, Soran O, et al. Results of a multidose phase I trial with Enbrel (Etanercept) p 75 TNF receptor fusion protein in patients with heart failure. Abstract]. J Am Coll Cardiol 1999.

45 Bozkurt B, Deswal A, Torre-Amione G, et al. Evidence of early reverse remodeling of the left ventricle in heart failure after treatment with Etanercept, p 75 TNF receptor fusion. Abstract]. 